\title{
Aging-related changes in cardiac extracellular matrix: implications for heart failure in older patients
}

\begin{abstract}
The aging population with heart failure (HF) is increasing worldwide. Hypertension (HTN) and myocardial infarction (MI) are the two main comorbidities leading to HF in the elderly (age $\geq 65$ years). Aging is progressive and results in cardiovascular changes that lead to an aging phenotype and negatively impact disease expression and response to therapy. Agingrelated changes contribute to adverse cardiac remodeling and $\mathrm{HF}$ with preserved ejection fraction (HFpEF). HTN also leads to HFpEF whereas MI leads to HF with reduced EF (HFrEF). Aging and concomitant HTN or MI accelerates the march to HF. The cardiac extracellular matrix (ECM) is critical for maintaining cardiac shape/function. A key mechanism in the development and progression of HF due MI and HTN involves adverse cardiac ECM remodeling. Disruption of the ECM network and dysregulation of ECM homeostasis and metabolism result in adverse cardiac remodeling with shape deformation and dysfunction that lead to HF, disability and death. Aging-related cardiac remodeling with superimposed progressive left ventricular remodeling leading to HFpEF or HFrEF in older patients is a persistent problem that has important therapeutic implications. Studies suggest that in the elderly, novel pathways can be targeted for optimizing therapy in HFrEF post-MI and HFpEF post-HTN. Therapeutic strategies that include targeting of adverse cardiac ECM remodeling could prevent/limit/reverse progression to HF in aging patients.
\end{abstract}

Volume 3 Issue 3 - 2015

\author{
Bodh I Jugdutt \\ Department of Medicine and Cardiovascular Research Group, \\ University of Alberta, Canada
}

Correspondence: B I Jugdutt, Cardiology Division of the Department of Medicine and Cardiovascular Research Group, 2C2 Walter MacKenzie Health Sciences Centre, University of Alberta, Edmonton, Alberta, T6G 2R7, Canada, Tel (780) 4390745, Fax (780) 437-3546, Email bjugdutt@ualberta.ca

Received: April 23, 2015 | Published: August 19, 2015

Keywords: aging, extracellular matrix, hypertension, myocardial infarction, cardiac remodeling, heart failure

Abbreviations: $\mathrm{CV}$, cardiovascular; ACC, american college of cardiology; ACE, angiotensin-converting enzyme; ADAM, a-disintegrin and metalloproteinase; AGES, advanced glycation products; AHA, american heart association; AngII, angiotensin II; ARB, angII-Type 1 receptor blocker; CMR, cardiac magnetic resonance; CRP, C-reactive protein; ESC, european society of cardiology; CGMP, cyclic guanosine monophosphate; ECM, extra cellular matrix; ENOS, endothelial nitric oxide synthase; GAG, glycosaminoglycan; Gal, galectin; GDF-15, growth differentiation factor 15; HF, heart failure; HFREF, HF with reduced ejection fraction; HFPEF, HF with preserved ejection fraction; HTN, hypertension; IL, interleukin; IL-1Ra, IL-1 receptor antagonist; INOS, inducible nitric oxide synthase; LV, left ventricular; MCSF, macrophage colony stimulating factor; MI, myocardial infarction; MMP, matrix metallo proteinase; MPO, myeloperoxidase; MT-MMP, membrane-type MMP; MRA, mineralocorticoid receptor antagonist; NGAL, neutrophil gelatinaseassociated lipocalin; NNOS, neuronal nitric oxide synthase; OPN, osteopontin; PCI, percutaneous coronary intervention; PKG, protein kinase G; RAAS, renin aldosterone angiotensin system; ROS, reactive oxygen species; TGF, transforming growth factor; SLPI, secretory leucocyte protease inhibitor; SPARC, secreted protein acidic and rich in cysteine; STEMI, ST segment elevation MI; TIMP, tissue inhibitor of MMP; TNF, tumor necrosis factor

\section{Introduction}

Heart failure (HF) is a major cause of disability and death worldwide and predominates in the older population. ${ }^{1-7}$ Since the $1950 \mathrm{~s}$, the HF burden in the older population has been been rising steadily in the United States of America, Europe and other developed countries. ${ }^{1,2,6-8}$ Importantly, this rising trend has persisted despite steady progress in HF therapies that are recommended in the management guidelines and updates published by the American Heart Association (AHA), American College of Cardiology (ACC), and European society of Cardiology (ESC). ${ }^{1-5,7}$ Left unchecked, this alarming upward trend could overtax the available resources of health care systems worldwide. ${ }^{9}$ Over the last 5 decades since the mid-1970s, four pertinent advances were made. First, population studies identified that antecedent myocardial infarction (MI) and hypertension (HTN) are the two leading causes of HF in older people who live in developed countries. ${ }^{1-5}$ Second, aging research suggested that the aging process per se might contribute to the toll of HF in the elderly aged $\geq 65$ years and older adults aged 45-64years. ${ }^{1}$ Third, translational research over the same period established that adverse cardiac remodeling plays a key role in the development and progression of HF and identified cardiac extracellular matrix (ECM) remodeling as a key underlying mechanism in both the development of HF and the subsequent march of adverse remodeling to end-stage disease in the aging patients. ${ }^{10-14}$ Fourth, other translational research indicated that, after MI and HTN, divergent remodeling of the myocardium and cardiac ECM result in two distinct types of HF (Figure 1) - HF with reduced ejection fraction $(\mathrm{HFrEF})$ and $\mathrm{HF}$ with preserved ejection fraction (HFpEF), respectively ${ }^{13-16}$-suggesting that different or combined therapeutic strategies are needed to halt the progression to HF in aging patients. ${ }^{14}$ Despite these advances, proven therapies that specifically target cardiac ECM remodeling in HF in aging patients are lacking. This review focuses on the role of cardiac ECM remodeling in HF of older patients and some potential therapeutic targets.

\section{Role of aging in cardiac and extracellular matrix remodeling}

Biological aging is a progressive process. In the cardiovascular (CV) system, early research evidence suggested that aging results in progressive physiological, biological and structural changes that lead to increased ECM and fibrosis, increased ventricular-arterial stiffening, left ventricular (LV) diastolic dysfunction, and HFpEF ${ }^{6,7,12-17}$ (Figure 2). A constellation of CV risk factors negatively impact the CV system 
throughout the aging process and fuel the adverse $\mathrm{CV}$ remodeling that leads to the development and progression of HF (Figure 3). In addition, the added insult of co-morbidities with aging further exacerbates and accelerates adverse remodeling and the march to HF (Figure 3). For optimal results, prevention strategies and therapeutic interventions need to separately target different incremental age groups and be evaluated in the different age groups in randomized clinical trials. ${ }^{18,19}$

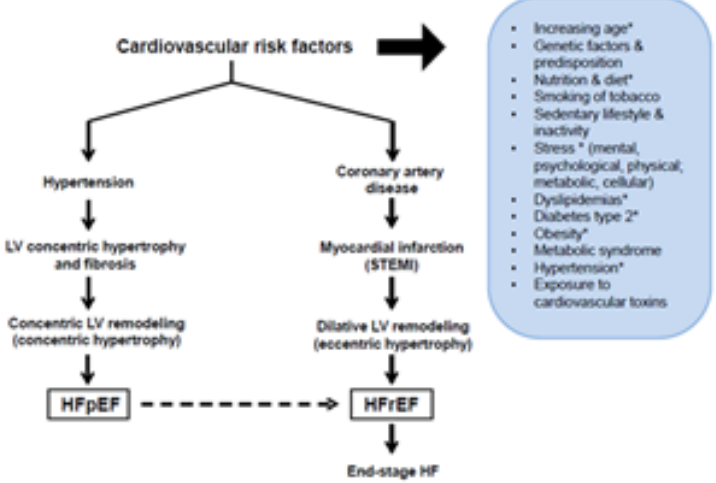

Figure I The two main types of cardiac remodeling and the march to heart failure in older patients. The two main co-morbidities in older patients, namely HTN and MI result in 2 divergent types of LV remodeling that lead to 2 distinct types of HF.The inset lists the main known CV risk factors. * Especially pertinent during the progressive aging process and subsequent march to HF.

EF: Ejection Fraction; HF: Heart Failure; LV: Left Ventricular; pEF: Preserved EF; rEF: Reduced EF; STEMI: ST-Segment Elevation Myocardial Infarction.

\section{Cardiovascular aging}

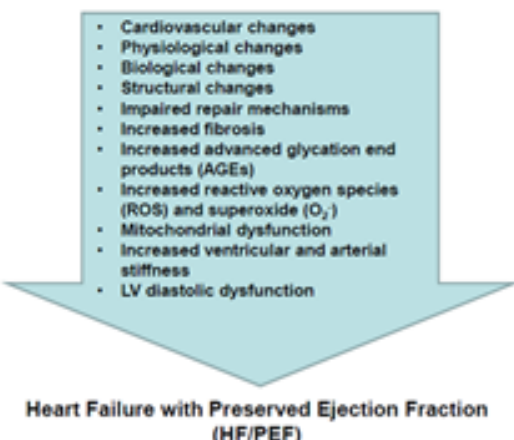

(HF/PEF)

Figure 2 Cardiac and matrix remodeling during cardiovascular aging and heart failure with preserved ejection fraction. Insets list the main cardiovascular, physiological, biological and structural changes with aging.

$\uparrow:$ Increased; ${ }^{-}$: Decreased; EF: Ejection Fraction; HF: Heart Failure; LV: Left Ventricular; pEF: Preserved EF; rEF: Reduced EF; STEMI: ST-Segment Elevation Myocardial Infarction.

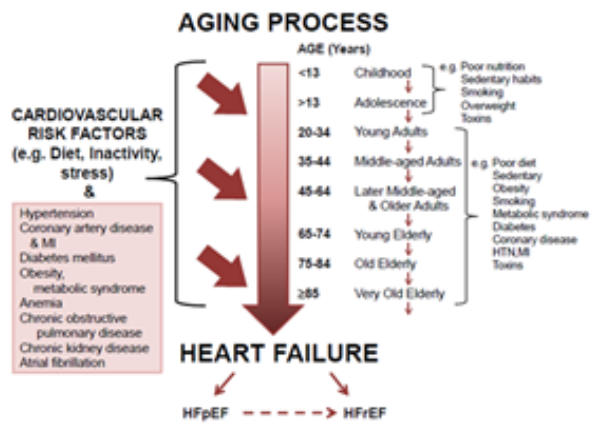

Figure 3 Prolonged exposure to risk factors and co-morbidities and the march to heart failure with aging.
A constellation of risk factors that impact the CV system throughout the aging process fuel adverse remodeling that in turn leads to progression and development of $\mathrm{HF}$, and the added insult of co-morbidities further exacerbates and accelerates adverse remodeling. The changing substrate in different age groups emphasizes the need for different prevention/treatment strategies tailored to the respective incremental groups to ensure optimal results.

EF: Ejection Fraction; HF: Heart Failure; LV: Left Ventricular; pEF: Preserved EF; rEF: Reduced EF; STEMI: ST-Segment Elevation Myocardial Infarction.

\section{Cardiac and ECM remodeling after myocardial infarction}

Cardiac remodeling following insults such as $\mathrm{MI},{ }^{10-12,14,20-32}$ $\mathrm{HTN}^{13}$ and various cardiomyopathies, ${ }^{3,16}$ involves progressive adaptive and maladaptive changes in cardiac structure, geometric shape and function that occur over time after the insult and lead to dysfunction. ${ }^{20-25}$ Cardiac remodeling after MI and HTN each contribute to about $50 \%$ of all cases of $\mathrm{HF}^{16,19}$ and has been extensively studied in patient and experimental models of HF due to these conditions. During the early stage of an MI, damage of muscle, ECM and microvasculature is followed by a staged healing process, which through a timed sequence of biochemical, molecular and cellular/ subcellular reactions over weeks, results in a fibrotic scar. ${ }^{10-12,27-30}$ Typically during post-MI healing, timed release of chemokines, cytokines, matrikines, growth factors including transforming growth factor- $\beta$ (TGF- $\beta$ ), and matrix metalloproteinases (MMPs) and other matrix proteins occurs. The timed release of these proteins serves to orchestrate inflammation, remodeling of myocardium and ECM, and fibrosis. ${ }^{10-12,27,28}$ Concurrent remodeling of cardiac structure and function is associated with complex biochemical, molecular, cellular and subcellular changes that further affect both cardiac muscle and ECM..$^{10}$ Importantly, remodeling spans all the phases of the healing process and is progressive and extends well beyond. ${ }^{10-12}$ During that time, multiple factors modulate remodeling of myocardium, ECM and vasculature post MI. ${ }^{10-12}$ In post-MI survivors, the remodeling process extends to other cardiac chambers, tissues, cells and molecules, resulting in a vicious cycle leading to end-stage HF. ${ }^{32}$

After a large anterior transmural MI or ST-segment-elevation MI (STEMI), remodeling is dramatic and highly dynamic, leading to rapid progression to dilative LV remodeling with systolic dysfunction and HFrEF and poor outcome. ${ }^{17-23,29-31}$ Rapid early remodeling of the infarcted wall with infarct expansion (i.e. thinning and dilatation) is followed by progressive remodeling of the whole LV and a march to LV dilatation, dysfunction, volume overload, wall thinning, eccentric hypertrophy, HF, disability and death (Figure 1). While studies have shown that reperfusion of an occluded coronary artery within 30minutes after onset of an STEMI can limit infarct size, LV dilative remodeling and dysfunction, few patients can be reperfused that early. With the more common scenario of reperfusion being achieved $\geq 90$ minutes from the onset of STEMI, the result is usually adverse LV remodeling with persistent $\mathrm{LV}$ dysfunction and $\mathrm{HF}^{31-39}$ The causes of this paradoxical adverse remodeling and dysfunction with delayed reperfusion despite recommended medical therapy in management guidelines, ${ }^{16,34}$ include infarct size and reperfusion damage with no-reflow and flow-function mismatch at the microvascular level, ${ }^{12,18,30,32-37}$ damage to the ECM, ${ }^{10-12,29-32,39,40}$ and inflammation in early and late phases of healing. ${ }^{10-12,30,38,41}$

\section{Effect of aging on cardiac and ECM remodeling after myocardial infarction}

Evidence suggests that, with aging, healing and repair of the damaged cardiac tissue after MI are impaired and result in augmented adverse remodeling affecting the entire left ventricle leading to $\mathrm{HFrEF}$, 
as well as remodeling of the left atrium and right ventricle. ${ }^{7,12,18,32}$ Several factors in aging hearts, such as increased reactive oxygen species (ROS) and superoxide (O2-), and increased myocardial angiotensin II (AngII), which in turn, exerts pro-inflammatory, pro-oxidant and pro-remodeling effects that lead to increased proinflammatory cytokines, MMPs and oxidative markers, and thereby modulate healing and repair. ${ }^{31}$

\section{Experimental studies}

In a key experimental study of aging in young and old mice suggested that aging-related dysregulation of ECM and impaired healing after reperfused MI results in adverse LV remodeling..$^{40,41}$ Several studies have shown that myocardial reperfusion after 90minutes of onset of MI is associated with an early increase in neutrophils and apoptosis that can augment myocardial damage ${ }^{10-12,35}$. In a study of aging using the canine model of reperfused MI, ${ }^{31} 120$ minutes of reperfusion after 90minutes of left anterior descending coronary artery occlusion was associated with increased pro-inflammatory markers such as TGF-b1, inducible-nitric-oxide-synthase (iNOS), cytokines interleukin (IL)6 and tumor necrosis factor (TNF)-a, decreased anti-inflammatory markers such as neuronal NOS (nNOS), endothelial NOS (eNOS), and IL-10, and evidence of increased cardiomyocyte damage (ischemic injury, infarct size, apoptosis, blood flow impairment, and no-reflow), adverse LV remodeling (LV dilatation and dysfunction; increased LV volumes and asynergy; increased infarct thinning; increased left atrial pressure; decreased ejection fraction and deceleration time) as well as adverse ECM remodeling with increased expression of MMP-9 and MMP-2, increased ratios of MMP-9/tissue inhibitor of metalloproteinase (TIMP)-3 and MMP-2/TIMP-1 suggesting increased ECM turnover), and increased matricellular proteins such as secretory-leucocyte-protease-inhibitor (SLPI), secreted protein acidic and rich in cysteine (SPARC), osteopontin (OPN) and a disintegrin and metalloproteinase (ADAM) -10 and -17 .

Studies in the rat model of reperfused MI also showed increase in these markers in the later phase of healing ${ }^{42,43}$ and the findings have been confirmed in the dog model. ${ }^{44,45}$ Taken together, these studies suggested that both early and late healing after reperfusion damage in older dogs lead to increased levels of matricellular proteins, proteolytic capacity, and pro-inflammatory activity in the infarct region; importantly, on the balance, aging appeared to be associated with impaired healing and augmented adverse ECM and cardiac remodeling and both systolic and diastolic dysfunction. In the same canine model, effects of AngII-blocker therapy with candesartan suggested that AngII modulates the age-dependent response to reperfused MI and the effectiveness of AngII-blocker therapy is blunted in older dogs. ${ }^{31,44,45}$ First, candestartan attenuated the agedependent increase in infarct size and apoptosis but was less effective in the old than young. ${ }^{31}$ Second, candesartan normalized LV dilatation and systolic dysfunction but was less effective in the old than young. Reasons for this reduced effectiveness of AngII-blocker therapy in the old versus young include:

i. The different substrate of the senescent heart, with aging-related cardiac remodeling including myocyte and LV hypertrophy, and interstitial fibrosis ${ }^{31}$ and

ii. Increased myocardial AngII in the senescent heart. ${ }^{46,47}$ This reduced efficacy of AngII-blocker therapy has profound clinical implications for therapy in the older adults and elderly and warrants clinical verification.

\section{Clinical studies}

In a key recent clinical study, Mahenke et al., ${ }^{39}$ assessed ECM turnover in patients with a first-time STEMI who were successfully reperfused by primary percutaneous coronary intervention (PCI). They carefully analysed serial serum samples taken before PCI and at 2 and 7days, 2months and 1year after the STEMI, for markers of collagen synthesis and degradation, and their relationship with LV infarct size, ejection fraction, and volumes using serial cardiac magnetic resonance (CMR) imaging at the same time points. They documented that significant increase in collagen type I degradation following STEMI was not accompanied by increase in collagen type I synthesis until 2 months and 1year. Importantly, in contrast to this delayed collagen type I synthesis, there was an immediate increase in collagen type III synthesis that was sustained for 1year. In addition, the N-terminal procollagen type I levels prior to PCI predicted adverse LV remodeling at all the CMR time-points. The findings indicated that net collagen type I degradation in the first week after STEMI was compensated by an early increase in collagen type III synthesis and subsequent increase in both collagen type I and III synthesis markers at 2 months and 1year. Together, the findings suggested that collagen turnover is persistently increased after STEMI that is successfully reperfused by primary PCI and this persistent collagen turnover might participate in the adverse remodeling. Of note, the patients in that study were aged $58 \pm 12$ (SD) years (i.e older adults and elderly).

\section{Role of inflammation in matrix and cardiac remodeling post MI}

Studies since the 1990s have addressed the mechanistic role of inflammation in matrix and cardiac remodeling after MI. Ten points deserve emphasis.

i. First, clinical and experimental studies support the idea that optimal healing/repair after MI is critical for survival with a favorable outcome. ${ }^{10-12}$

ii. Second, besides its well documented role during early $\mathrm{MI},{ }^{27,28}$ inflammation plays a critical role in modulating healing/repair as well as matrix and cardiac remodeling after MI. ${ }^{10-12,48}$

iii. Third, inflammation is tightly regulated to ensure adequate healing/repair and scar formation and dysregulion leads to excessive and/or prolongation or expansion of inflammation resulting in defective scar formation and exacerbation of adverse ECM and LV remodeling. Both too little or too much inflammation can therefore be harmful. ${ }^{41,49}$

iv. Fourth, the regulated inflammatory reaction is time-dependent, staged and highly dynamic; different monocyte and macrophage phenotypes modulate clearance of dead cells and matrix debris in the early phase, and activation of pathways for optimal healing/ repair and scar formation in the late phase. ${ }^{41,48,49}$ The resolution of inflammation in the late phase involves activation followed by inhibition (negative regulation), containment of the infarct area, and resolution, ${ }^{48}$ and its robustness is a key factor influencing outcome.

v. Fifth, in non-reperfused MI, or MI with permanent coronary artery occlusion, neutrophils infiltrate the infarcted zone and release, in tandem, four subsets of membrane-bound granules such as secretory vesicles and gelatinase, specific and azurophilic granules. ${ }^{50}$ The granules contain various factors including proteases, ECM proteins and soluble mediators of inflammation that modulate ECM and myocardial remodeling. For example, gelatinase granules release MMPs. ${ }^{50,51}$ such as MMP-9 ${ }^{52}$ that degrade ECM. The specific granules release neutrophil gelatinase-associated lipocalin (NGAL) which inhibits MMP-9- 
induced degradation and thereby modulates ECM and myocardial remodeling. ${ }^{51,52}$ Importantly, NGAL levels increase in plasma of patients with acute MI and in infarct and non-infarct zones in experimental HF. ${ }^{53,54}$

vi. Sixth, activated neutrophils and monocytes post MI produce myeloperoxidase (MPO) and exacerbate ECM and myocardial remodeling, ${ }^{42}$ likely through generation of oxidants including reactive chlorinating species and activation of MMPs. ${ }^{55}$ Interestingly, plasma MPO levels predict MI risk and adverse events in patients with chest pain. ${ }^{56}$

vii. Seventh, reperfusion after 90 minutes of $\mathrm{MI}$ is associated with a surge of neutrophils and apoptosis. ${ }^{35}$ As mentioned before, reperfused STEMI is associated with increased pro-inflammatory and anti-inflammatory markers, MMPs and matricellular proteins that modulate ischemic injury, infarct size, apoptosis, blood flow impairment and no-reflow, adverse LV and ECM remodeling. ${ }^{31}$ Importantly, clinical studies have verified increased infarct size, LV remodeling, inflammation, and ECM remodeling after reperfused STEMI. ${ }^{36-39}$

viii. Eighth, monocytes and macrophages are the dominant inflammatory cells during healing/repair and regulate the process and thereby modulate the march to ECM/cardiac remodeling and HF post MI. . $^{41,48,49,57,58}$ Monocytes appear to differentiate into macrophages (or dendritic cells) in response to environmental cues. Studies have identified two populations of monocytes, namely pro-inflammatory Ly-6Chigh monocytes that dominate the early phase and the pro-resolution and pro-repair Ly-6Clow monocytes that dominate the late phase of healing. While the Ly-6Chigh monocytes remove necrotic debris and secrete inflammatory cytokines, ROS and matrix degrading proteases, the Ly-6Clow monocytes trigger angiogenesis, collagen/ECM synthesis by myofibroblasts and healthy infarct scar formation. ${ }^{41,49}$ Imbalance in the actions of the monocytes/macrophages can result in delayed resolution of inflammation, impaired healing, augmented ECM remodeling, and a weak scar.

ix. Ninth, macrophages appear to polarize to different phenotypes with different gene expression profiles and functional characteristics, depending on spatial and temporal upregulation of cytokines, chemokines and growth factors in the two phases of post-MI healing/repair and thereby modulating the process. ${ }^{59}$ Upregulation of macrophage-colony stimulating factor (MCSF) in the early inflammatory phase induces monocyte differentiation with polarization to classical pro-inflammatory M1 macrophages that secrete T1-helper cell Th1 cytokines. ${ }^{48}$ The activated M1 macrophages in turn secrete inflammatory mediators, ROS and nitrogen intermediates, chemokines and growth factors and thereby modulate fibroblast function, collagen turnover and angiogenesis, and augment inflammation, ECM degradation and clearance of dead cells and matrix debris. ${ }^{49,57}$ In class A scavenger receptor null mice, enhanced M1 macrophage polarization resulted in enhanced LV dilation and dysfunction, cardiac fibrosis, and increased M1 cytokines including IL-1 $\beta$, IL-6 and TNF- $\alpha .{ }^{60}$ Secretion of IL- $1 \beta$ in the M1 phase induces MMP-9, which promotes secretion of inflammatory cytokines and ECM degradation. Together, the findings suggest that persistent M1 macrophage activation can exacerbate LV remodeling and dysfunction post MI.

$\mathrm{x}$. Tenth, in the late phase of healing/repair, macrophages polarize to activated M2 macrophages akin to Th2 cells, ${ }^{57}$ that lead to enhanced phagocytic activity and anti-inflammatory activity, with upregulation of IL-10, IL-4, and TGF- $\beta 1$, decoy type 2 IL-1 receptor and IL-1 receptor antagonist (IL-1Ra), and thereby promote resolution with removal of inflammatory leukocytes, ${ }^{61}$ and resolution of ECM deposition, fibroblast proliferation, and angiogenesis which are essential for tissue repair. ${ }^{61}$ It follows that timely shift and balance between M1 and M2 macrophage phenotypes is important for the formation of a stable scar post MI. Prolonged and excessive activation of M1 macrophages yield uncontrolled inflammation and ECM degradation, which in turn leads to adverse remodeling and cardiac rupture. On the other hand, persistent activation of M2 macrophages leads to excessive fibroblast proliferation and ECM deposition, which is a hallmark of cardiac fibrosis and influences structural, biochemical, mechanical, and electrical properties of the myocardium. ${ }^{61}$ Further study is needed to determine if the M1/M2 ratio might provide a potential marker of adequate healing/repair and outcome post MI.

\section{Role of MMP/ TIMP balance/imbalance in ECM and cardiac remodeling post MI}

The cardiac ECM proteins, such as collagen, elastin, fibrillin, fibronectin, proteoglycans, and matricellular proteins, are finely organized in a complex 3-dimensional matrix assembly that ensure normal cardiac structure and function. ${ }^{10,11,62-64}$ The organized interstitial network of collagen fibers provides the architectural support for cardiac myocytes, vascular channels and other cells, as well as the milieu for cell migration, growth, differentiation and interaction. An abundance of cardiac fibroblasts regulate ECM synthesis and deposition, mediate ECM degradation and turnover via MMPs and TIMPs, and maintain tension. ${ }^{62}$ Regulation of normal ECM remodeling with continuous ECM synthesis and degradation ensures maintenance of ECM homeostasis, cardiac shape and function via a fine balance between MMPs and TIMPs, and thereby prevents excessive ECM degradation that results in adverse remodeling.

The MMPs which represent the main proteolytic system for ECM degradation in the heart, are zinc-dependent endopeptidases that degrade ECM components such as collagens, fibronectin, proteoglycans, laminin and gelatin..$^{10,11}$ Nearly 28 MMPs but only 4 TIMPS have been described and MMP activity is regulated posttranslationally by the TIMPs. ${ }^{65}$ Four of the 5 classes of MMPs (collagenases, gelatinases, stromelysins and elastase) are secreted as latent pro-MMPs that bind ECM proteins and only become active upon cleavage of the propeptide domain via a cysteine switch mechanism involving serine proteases, trypsin, chymotrypsin and plasmin. ${ }^{65}$ Importantly, several MMPs can be activated by other pro-MMPs and trigger activation of more pro-MMPs leading to proteolysis. The fifth class of MMPs includes membrane-type MMPs (MTMMPs) which are activated upon positioning in the cell membrane and retain the propeptide domain needed for activation and TIMPbinding. ${ }^{65}$ Injury triggers increased MMP expression, from basal levels in myocytes, fibroblasts, myofibroblasts and endothelial cells but also in inflammatory cells such as neutrophils, monocytes and macrophages. While most cells express TIMPs, TIMP-4 expression is highest in human myocardium. Besides inhibiting MMPs, the TIMPs are multifunctional and exert pro-growth, anti-apoptotic and antiangiogenic effects. ${ }^{65}$

After MI, evidence indicates that LV remodeling is a main underlying mechanism for LV dilatation, HF and death, and ECM disruption is pivotal in dilative remodeling while AngII drives both ECM and LV remodeling. ${ }^{10-12}$ A major pathway leading to ECM and dilative LV remodeling is through MMP/TIMP imbalance reflected in an increased MMP/TIMP ratio. ${ }^{10-12}$ The main MMPs implicated 
in cardiac remodeling include collagenases MMP-1, MMP-8 and MMP-13, gelatinases MMP-2 and MMP-9, stromelysin MMP-3, and membrane-type MMP-14. After acute MI, a sharp rise in MMPs leads to rapid ECM degradation involving mainly fibrillary collagens in mature ECM (mostly cross-linked, thick and rigid type I collagen), and results in MMP/TIMP imbalance with increased ratio, adverse ECM and early LV remodeling with acute infarct expansion. This is followed by slow synthesis, deposition of immature, thin and elastic type III collagen, and subsequent slow maturation during healing/ repair and beyond, resulting in further adverse LV remodeling. ${ }^{10-12}$ This delayed replacement by rigid collagen type I and persistence of elastic collagen type III during healing/repair results in a vulnerable window of several weeks for adverse remodeling but also offers an opportunity for applying therapeutic interventions to limit remodeling.

Whereas MMP and TIMP levels subside over several days after acute MI, chronically higher MMP than TIMP levels can result in persistent ECM degradation and dilative LV remodeling, while higher TIMP than MMP levels can lead to increased ECM and fibrosis in the non-infarct zone resulting in diastolic dysfunction.

Six advances using genetic models support the aforementioned concepts and deserve mention. First, disruption of MMP-1, a collagenase from fibroblasts that has high affinity for fibrillar collagens and preferentially degrades collagen types I and III after MI, ${ }^{66}$ results in LV dilatation and dysfunction. ${ }^{67}$ MMP-1 synthesis is increased in $\mathrm{MI}^{67}$ and transgenic expression of MMP-1 inhibits fibrosis and the transition to HF in LV pressure overload. ${ }^{68}$ Second, deletion of TIMP1 , which is normally expressed by cardiac fibroblasts and myocytes and co-localizes with MMP-1 in myocardium, results in dilative remodeling post $\mathrm{MI}$ in mice. ${ }^{69}$ Importantly, increased TIMP-1 levels correlate with markers of LV remodeling and HF in patients with MI and HTN. ${ }^{69-71}$ Third, both MMP-2 (gelatinase A) from myocytes, macrophages and myofibroblasts, and MMP-9 (gelatinase B) from neutrophils, macrophages, lymphocytes, cardiac myocytes, vascular smooth muscles cells, endothelial cells and fibroblasts have been implicated in post-MI remodeling. ${ }^{72-74}$

Fourth, MMP-9 is somewhat unique in that it can process full length interstitial collagens as well as other substrates without the activation cleavage step for proteolysis, and not just collagen that has already been cleaved by collagenases such as MMP- $1 .^{75}$ MMP-9 also interacts with inflammatory response elements such as activator protein-1, specificity protein-1 and NF-kB and participates in the post-MI inflammatory response. ${ }^{75}$ Furthermore, both pharmacological inhibition and deletion of MMP-9 attenuate post-MI LV dilatation and dysfunction ${ }^{73-76}$ while deletion stimulates angiogenesis in the infarct zone. ${ }^{76}$ MMP-9 levels correlate with inflammatory markers (such as IL-6, hs-CRP and fibrinogen) and CV mortality ${ }^{77}$ as well as with LV hypertrophy, MI, adverse remodeling with LV dilatation and dysfunction and HFrEF, and HFpEF. ${ }^{80}$ MMP-9 may therefore provide a prognostic biomarker for $\mathrm{CV}$ mortality. ${ }^{77}$ and adverse LV remodeling. ${ }^{78-81}$

Fifth, aged TIMP-3 null mice show increased MMP-9, ECM degradation and LV dilatation, cardiomyocyte hypertrophy and LV dysfunction..$^{82}$ TIMP-3 also regulates inflammation and inhibits ADAM-17 and -10 which can alter integrins (cell-surface matrix receptors), disrupt cell-matrix interactions, degrade ECM and contribute to LV dilation. ${ }^{83}$ These ADAMs also interact with inflammatory cytokines and alter MMPs, and thereby impact LV remodeling and/or injury. ${ }^{82}$ This finding underscores the fact that interactions between matrix proteins and inflammatory cytokines can modulate ECM remodeling. ${ }^{84}$ Sixth, while the role of MMP-3 (stromelysin-1) from myocytes remains unclear, elastase appears to modulate ECM degradation through activation of MMP-2, -3 and -9 and inactivation of TIMP- $1{ }^{74}$ and elastase inhibition before reperfusion was shown to reduce infarct size. ${ }^{75}$

In summary, in survivors of MI and HTN, disruption of ECM or dysregulation of ECM homeostasis and metabolism augment adverse cardiac remodeling with shape deformation and dysfunction that result in HF, disability and death. ${ }^{10,84}$ A healthy cardiac ECM is therefore critical for preservation of cardiac shape and function, and adverse ECM remodeling plays a critical role in the march to HF. ${ }^{10,84}$

\section{Cardiac and ECM remodeling in hypertension}

Remodeling in patients with HTN progresses at a slower pace than with MI, and in response to chronic LV pressure overload results in concentric, hypertrophic and non-dilative LV remodeling; however, the latter may progress to LV dilative remodeling with eccentric hypertrophy and $\mathrm{HF}^{7,26}$ which over time, may result in end-stage heart disease with congestive HF (Figures 1 \& 3). As mentioned, a hallmark in hearts of hypertensive patients is excessive deposition of ECM with fibrosis, ${ }^{11,15}$ increased LV stiffness and typically HFpEF. ${ }^{11,15,16}$

In HTN, myocardial fibrosis which implies excessive ECM and collagen deposition, is mediated by well recognized mechanical and humoral mechanisms and leads to increased myocardial stiffness, LV diastolic dysfunction and HFpEF. ${ }^{81,85}$ Reactive fibrosis in HTN leads to increased stiffness ${ }^{86}$ and impared electrical activity. ${ }^{87}$ The regulators and suppressors of reparative fibrosis during healing/repair after MI have been reviewed, ${ }^{48}$ but the "braking" and "stop" signals in the infarct and non-infarct zones remains unclear. As discussed, net ECM degradation dominates the early phase of post-MI healing/repair and net ECM deposition, collagen synthesis and maturation dominate the later phase. In HTN, the "braking" and "stop" signals of reactive fibrosis also need study.

\section{Collagen turnover and markers}

As reviewed elsewhere, ${ }^{11,12}$ collagen turnover in cardiac ECM is regulated by fibroblasts and myofibroblasts. The fibroblasts and myofibroblasts synthesize and secrete preprocollagen type I and III as pro- $\alpha$-collagen chains which form the triple helix structure of procollagens in the rough endoplasmic reticulum. ${ }^{11,88}$ Procollagen molecules are secreted from the Golgi complex into the interstitial space where cleavage of the end-terminal propeptide sequences allows collagen fiber formation. Post-translational modification of fibrillar collagen with addition of cross-links increases stability. Since specific procollagen $\mathrm{N}$ - and $\mathrm{C}$-proteinases release the two terminal propeptides (i.e. amino (N)-propeptide and carboxy (C)-propeptide) of procollagen molecules into the circulation, ${ }^{89}$ the levels of these cleaved collagen propeptides can provide an indirect index of fibrillar collagen synthesis and deposition in patients with HTN.

Markers of synthesis include procollagen type I carboxy-terminal propeptide (PICP), procollagen type I amino-terminal propeptide (PINP), and procollagen type III amino-terminal propeptide (PIIINP). ${ }^{11,84}$ Serum PICP levels are elevated in both MI $^{90}$ and diastolic $\mathrm{HF}^{81}$ and correlate with the collagen fiber deposition in LV hypertrophy of spontaneously hypertensive rats. ${ }^{91}$ While PIIINP has been used as a marker of type III synthesis and to predict cardiac events and mortality, it may underestimate type III synthesis. ${ }^{92}$ Markers of collagen degradation include collagen type I carboxyterminal telopeptide (CITP) and MMPs. High plasma CITP levels in post-MI patients correlate with poor outcome..$^{92}$

Galectin-3 (Gal-3) which is expressed by activated macrophages and induces fibroblast proliferation and increased deposition of 
collagen type I and plays a role in the regulation of cardiac fibrosis and remodeling, has emerged as a potential marker of cardiac fibrosis in hypertrophied hearts. ${ }^{93}$ Post MI, Gal-3 expression is increased in the infarct zone of mice ${ }^{94}$ and in experimental and clinical $\mathrm{HF}^{84,95}$ but more studies in HTN are needed. Fibroblasts, which are the predominant non-myocyte cells in the heart and regulate ECM homeostasis in healthy and diseased hearts, play a critical role in fibrosis of MI, HTN and aging. ${ }^{62,95,96}$ Importantly, activated fibroblasts undergo phenotypic transformation into myofibroblasts that express contractile proteins, including $\alpha$-smooth muscle actin, vimentin and desmin. Cardiac myofibroblasts are more sensitive to pro-inflammatory cytokines and hormones that are upregulated in remodeling hearts. ${ }^{97}$ Fibroblasts also act as "sentinel cells" that function as local immune modulators, ${ }^{98}$ and contribute to cardiac electrophysiology. It follows that cardiac fibroblasts and myofibroblasts may be potential candidates for optimizing healing/repair in post-MI survivors.

\section{Therapy and modulators of post-MI remodeling and markers with aging}

The modulators of post-MI remodeling and markers with aging have been reviewed. ${ }^{99-101}$ As mentioned before, the majority of patients with HTN, MI and HF are older adults or elderly and old patients develop fibrosis and myocardial stiffness that result in diastolic dysfunction with HFpEF even in the absence of MI or HTN. Importantly, specific therapy for HFpEF is lacking. Clinical studies that have tested inhibitors of collagen synthesis for limiting cardiac fibrosis have failed. Encouraged by successful attenuation of postMI LV remodeling with broad-spectrum as well as selective MMP inhibitors in post-MI mice and pigs, and chronic HF patients, ${ }^{102}$ a larger clinical study of MMP inhibition initiated after acute STEMI failed to limit LV remodeling. ${ }^{102}$

Renin-aldosterone-angiotensin system (RAAS) inhibitors such as angiotensin-converting enzyme (ACE) inhibitors, AngII-type 1 receptor blockers (ARBs) and mineralocorticoid receptor antagonists (MRAs) can all limit fibrosis ${ }^{10-12}$ and combination therapy is often necessary in the elderly. However, their use in patients with MI and HTN has not prevented the march to HF. The attractive idea of a dual-action molecule that targets both natriuretic peptide and AngII pathways was tested with LCZ696, which combines neprilysin and the ARB valsartan. LCZ696 was shown to benefit patients with HFpEF in a phase II trial ${ }^{103,104}$ and is being evaluated in patients with HFrEF in a phase III trial. ${ }^{103,104}$ Since is associated with RAAS remodeling, ${ }^{105}$ whether dual pathway inhibition and other RAAS and novel therapies may be more effective in elderly HF patients needs study.

\section{Aging and cardiac ECM remodeling}

The traditional view is that four main features make up the aging phenotype, and these are increased concentric remodeling, increased mass to volume ratio, increased ECM (fibrillary collagen content), and decreased diastolic function and relaxation. ${ }^{14,17}$ Ten points in aging research that support the current concepts need emphasis. First, aging-induced ECM remodeling begins with ECM regulation and collagen synthesis, deposition, maturation and degradation. Increased deposition is dependent on interactions among signaling pathways, protein synthesis, post-translational modification and enzyme activity. Second, aging induces progressive loss of myocytes and myocyte hypertrophy, ${ }^{106,107}$ left atrial dilatation and atrial fibrillation, ${ }^{108}$ and results in HFpEF. ${ }^{109}$ Third, findings in the senescence-accelerated mouse support the idea that cardiac fibrosis leads to LV diastolic dysfunction and depressed compliance independent of vascular stiffening. ${ }^{110}$ Compared to age-matched senescence-resistant mice, 6-month old senescence-accelerated mice showed reduced left-atrial/
LV filling ratio, increased end-diastolic pressure and diastolic stiffness, and LV fibrosis but no change in ventricular/vascular coupling ratio, ejection fraction or LV size. ${ }^{110}$ Fourth, naked mole rats with long life spans, ${ }^{111}$ old male rats show no change in left-atrial/LV filling ratio whereas old female rats develop diastolic dysfunction. ${ }^{112}$

Fifth, increased cross-linking of amino groups in fibrillar collagen induced by reducing sugars that yield advanced glycation products (AGES) is seen with aging and pathological remodeling. ${ }^{113,114}$ Interestingly, SPARC binds to protocollagen and mediates mature cross-linking, ${ }^{115}$ and SPARC ablation results in age-dependent decreased collagen content and cross-linked collagen, and decreased fibrosis with pressure overload. ${ }^{116,117}$ SPARC null mice have been shown to develop defective scars and cardiac rupture after MI. ${ }^{118}$ Sixth, with regard to ground substance, aging has been reported to either decrease ${ }^{119}$ or have no effect on glycoaminoglycans (GAGs), ${ }^{120}$ increase the non-sulfated GAG hyaluronan (hyaluronic acid) and decrease chondroitin sulfate, ${ }^{120}$ and increase the GAG heparin sulfate. ${ }^{121}$ Seventh, aging results in increase in the adhesive protein fibronectin in pressure and volume overload and MI. ${ }^{122-125}$

Eighth, aging leads to cardiac fibrosis even in the absence of comorbidities. Several studies have shown decreased myocardial collagen synthesis with aging, suggesting post-translational modification and/or decreased degradation. ${ }^{126-129}$ In contrast, collagen synthesis increases in HTN and pressure-overload hypertrophy. ${ }^{130-132}$ Ninth, the latest of the MMPs, MMP-28 (epilysin) is expressed constitutionally in macrophages of adult hearts, and is increased in older mice but deletion amplifies the inflammatory and ECM responses with aging ${ }^{133}$ and augments dysfunction and rupture post MI. ${ }^{134}$ Tenth, in sheep with pacing-induced heart failure, older sheep aged 8years show decreased LV collagen content, increased MMP-2 and decreased TIMP-3 and -4, and increased SPARC compared to younger sheep aged 1.5years. ${ }^{135}$ However, serum PICP was increased in both age groups. ${ }^{135}$

\section{Recent advances towards developing therapy for HFpEF}

The previous discussion has focused on the role of cardiac ECM remodeling in $\mathrm{HF}$ of older patients and some potential therapeutic targets. The two main types of adverse remodeling and HF encountered in the elderly population (HFpEF and HFrEF) have been underscored. The concept of lifelong exposure to a constellation of $\mathrm{CV}$ risk factors throughout the aging process in fueling adverse remodeling that in turn leads to progression and development of HF, and the role of the added insult of co-morbidities in exacerbating and accelerating adverse remodeling with aging have been emphasized (Figures 1-3). The lack of specific therapy to limit aging-induced adverse remodeling and the march to HFpEF in 2015 underlines the need for more research.

A recent report on developing therapies for reducing hospitalization and mortality in patients with HFpEF patients hosted by the Food and Drug administration Bureau in the United States recognized the increasing prevalence of HFpEF, increasing risk for adverse outcomes, the lack of specific approved therapy, the lack of animal models for the study of HFpEF, the need to understand the role of comorbidities, and the multiplicity of potential CV structural targets, mechanisms and pathways. ${ }^{136}$ The participants endorsed better understanding of pathophysiological pathways and better identification of therapeutic targets. ${ }^{136}$ While they debated whether HFpEF represents a collection of comorbidities, the importance of $\mathrm{CV}$ changes with aging was not highlighted in the report. ${ }^{136}$

Of note, in the HFpEF trials, the LVEFs were $>40-50 \%$, mostly $>$ $45 \%$, and fewer with LVEF $>40 \%$ (i.e. the lower range). ${ }^{136}$ In trials with 
the ARB irbesartan in $\mathrm{HFpEF}^{137,138}$ and the ACE-inhibitor candesartan in $\mathrm{HF}^{137,139}$ showed lower $\mathrm{CV}$ mortality $(70 \%)$ in $\mathrm{HFpEF}^{137,139}$ and higher CV mortality (83\%) in HFrEF. ${ }^{137,139}$ Trials with ACE-inhibitors, ARBs, digoxin, beta-blockers, spironolactone and sildenafril did not lower mortality in HFpEF while results with LCZ696 are awaited. ${ }^{136}$ Importantly, Campbell et al., ${ }^{137}$ suggested that HFpEF extends beyond age and comorbidities. Paulus et al., ${ }^{140}$ recently underscored the role of systemic inflammation related to comorbidities and postulated a cascade of 5 steps leading to HFpEF. In their construct, the high prevalence of comorbidities (such as overweight/obesity, diabetes mellitus, chronic obstructive pulmonary disease, and salt-sensitive HTN) induce a systemic pro-inflammatory state which causes coronary microvascular endothelial inflammation, that in turn reduces NO bioavailability, cyclic guanosine monophosphate (cGMP), and protein kinase $\mathrm{G}(\mathrm{PKG})$ activity in adjacent cardiomyocytes. The low PKG activity in turn favors hypertrophy and increased resting tension due to reduced phosphorylation of titin. Finally, the stiff cardiomyocytes and interstitial fibrosis contribute to high diastolic LV stiffness and HFpEF. ${ }^{140}$ They suggest that diagnostic algorithms should include comorbidities, plasma markers of inflammation or vascular hyperemic responses and therapy should aim at restoring myocardial PKG activity. ${ }^{140}$ Whether co-morbidities might explain the failure of previous trials in $\mathrm{HFpEF}$ is unclear.

A recent study of elderly adults (mean age 73-74years) showed that adverse LV remodeling predicts incident HF and mortality. ${ }^{141}$ The majority of the patients had $\mathrm{EF} \geq 45 \%$. The authors used a combinatorial assessment of LV chamber size and wall mass to identify older adults with HF and concluded that the addition of relative wall thickess (RWT or ratio of septal plus posterior wall thickness to end-diastolic dimension by echocardiography) to the analysis of LV remodeling and outcome only had incremental value when the LV is not enlarged. ${ }^{141}$ In a previous report on mostly older patients, the majority of patients with HFpEF showed LV hypertrophy or concentric remodeling, left atrial dilatation, and diastolic dysfunction. ${ }^{142}$ Other biomarkers of HFpEF have been reviewed elsewhere. ${ }^{99,100,143}$ The biomarkers that appeared most promising included those of myocyte stress, inflammation, ECM remodeling, growth differentiation factor 15 (GDF-15), cystatin C, resistin, and galectin- $3 .{ }^{143}$ Soluble ST2 is considered a prognosis biomarker in $\mathrm{HF}$ and is involved in multiple pathways including cardiac strain, inflammation, necrosis and remodeling. ${ }^{144}$ The new biomarker ST2 belongs to the IL-1 superfamily involved in inflammation, and increased soluble ST2 in the circulation acts as a decoy receptor for IL-33, thereby blocking its antinecrotic and antiremodeling effects, and promoting fibrosis and ventricular dysfunction. ${ }^{144}$

\section{Acronyms for the types of HF}

It should be noted that the literature on the use of the acronyms for the 2 major types of HF in older patient populations has been evolving and is still being debated. Paulus has used HFPEF and HFREF, ${ }^{15,16,140}$ as have the past ESC and AHA/ACC guidelines. ${ }^{3-5}$ Recent publications favor the acronyms $\mathrm{HFpEF}$ and $\mathrm{HFrEF}^{136}$ and these are used here.

\section{Conclusion and future directions}

Cardiac remodeling is multifactorial, highly dynamic and timedependent. Dysregulated ECM homeostasis in survivors of MI and HTN leads to adverse ECM and cardiac remodeling, LV dysfunction and poor outcome. Defective ECM and fibrosis with increased crosslinking can augment adverse LV remodeling and systolic/diastolic dysfunction. Decrease in ECM and fibrosis and/or defective ECM (with increased collagen type III and decreased or abnormal crosslinking) can lead to more adverse LV remodeling with predominant systolic dysfunction and even LV rupture. After STEMI, combined damage of muscle, ECM, and microcirculation and not just ECM drives dilative LV remodeling with HFrEF. In HTN, combined LV hypertrophy and excess ECM/fibrosis drives concentric LV remodeling with $\mathrm{HFpEF}$, and later mixed LV remodeling with HFrEF. Despite divergent types of remodeling post MI and HTN (i.e eccentric versus concentric; Figures $1 \& 3$ ), they may converge due to changes with aging and other co-morbidities (Figure 3).

Importantly, despite conventional therapy, both types of remodeling and HF progress to end-stage HF, disability and death (Figures $1 \& 3$ ). Sound knowledge of modulators and markers of matrix remodeling is therefore critical in efforts to identify targets to prevent, interrupt/ limit/reverse the progression to end-stage $\mathrm{HF}^{99,100,143}$ for review. It is important to remember that therapy with RAAS inhibitors and betablockers decrease ECM and may be beneficial in HTN and remote MI but the benefits may be blunted with aging. Identifying a specific therapeutic target may be made difficult because multiple pathways are often involved and co-morbidities with more pathways are often involved. For optimal benefit in elderly patients, future strategies may need combined approaches comprising novel substrates, targets and regimens, mechanical approaches, and matrix-tissue engineering, regeneration and transplants. ${ }^{84}$ Efforts to prevent, interrupt, limit or reverse the march of cardiac remodeling to end-stage HF in any age group should first be to identify key modulators, early markers, and potential therapeutic targets in post-MI and post-HTN remodeling processes in aging patients. More translational and clinical research into cardiac aging and testing of therapies in aging animal groups and elderly patient groups is needed.

\section{Acknowledgements}

I am indebted to Bernadine A Jugdutt for expert assistance with the figures.

\section{Conflicts of interest}

Author declares there are no conflicts of interest.

\section{Funding}

None.

\section{References}

1. Lloyd-Jones D, Adams RJ, Brown TM, et al. Heart Disease and Stroke Statistics - 2010 Update: A Report from the American Heart Association Statistics Committee and Stroke Statistics Subcommittee. Circulation. 2010;121:e46-e215.

2. Roger VL, Go AS, Lloyd-Jones DM, et al. Heart disease and stroke statistics-2012 update: a report from the American Heart Association. Circulation. 2012;125(1):e2-e220.

3. Hunt SA, Abraham WT, Chin MH, et al. 2009 focused update incorporated into the ACC/AHA 2005 Guidelines for the Diagnosis and Management of Heart Failure in Adults: a report of the American College of Cardiology Foundation/American Heart Association Task Force on Practice Guidelines: developed in collaboration with the International Society for Heart and Lung Transplantation. Circulation. 2009;119(14):e391-479.

4. Jessup M, Abraham WT, Casey DE, et al. Focused update: ACCF/ AHA Guidelines for the Diagnosis and Management of Heart Failure in Adults: a report of the American College of Cardiology Foundation/ American Heart Association Task Force on Practice Guidelines. Circulation. 2009;119:1977-2016.

5. McMurray J, Adamopoulos S, Anker SD, et al. ESC Guidelines for the diagnosis and treatment of acute and chronic heart failure 2012The task force for the Diagnosis and Treatment of Acute and Chronic 
Heart Failure of the European Society of Cardiology. Developed in collaboration with the Heart Failure Association (HFA) of the ESC. Eur J Heart Fail . 2012;14(8):803-869.

6. Jugdutt BI. Aging and heart failure: changing demographics and implications for therapy in the elderly. Heart Failure Rev. 2010;15(5):401-405.

7. Jugdutt BI. Heart failure in the elderly: advances and challenges. Expert Rev Cardiovasc Ther. 2010;8(5):695-715.

8. Ho KK, Pinsky JL, Kannel WB, et al. The epidemiology of heart failure: the Framingham study. J Am Coll Cardiol . 1993;22(4 Suppl A):6A-13A.

9. Stevenson LW. Projecting heart failure into bankruptcy in 2012? Am Heart J. 2011;161(6):1007-1011.

10. Jugdutt BI. Ventricular remodeling post-infarction and the extracellular collagen matrix. When is enough enough? Circulation. 2003;108(11):1395-1403.

11. Jugdutt BI. Remodeling of the myocardium and potential targets in the collagen degradation and synthesis pathways. Curr Drug Targets Cardiovasc Haematol Disord. 2003;3(1):1-30.

12. Jugdutt BI. Aging and remodeling during healing of the wounded heart: current therapies and novel drug targets. Curr Drug Targets. 2008;9(4):325-344.

13. Jugdutt BI. Aging and Heart Failure: Mechanisms and Management Springer, New York, USA. 2014.

14. Jugdutt BI. Clinical effectiveness of telmisartan alone or in combination therapy for controlling blood pressure and vascular risk in the elderly. Clin Interv Aging. 2010;5:403-416.

15. Paulus WJ, Tschöpe C, Sanderson JE, et al. How to diagnose diastolic heart failure: a consensus statement on the diagnosis of heart failure with normal left ventricular ejection fraction by the Heart Failure and Echocardiography Associations of the European Society of Cardiology. Eur Heart J. 2007;28(20):2539-2550.

16. Dickstein K, Cohen-Solal A, Filippatos G, et al. ESC guidelines for the diagnosis and treatment of acute and chronic heart failure 2008: the Task Force for the diagnosis and treatment of acute and chronic heart failure 2008 of the European Society of Cardiology. Eur J Heart Fail. 2008;10(10):933-989.

17. Lakatta EG, Levy D. Arterial and cardiac aging: major shareholders in cardiovascular disease enterprises. Part I. Aging arteries: a "set up" for vascular disease. Circulation. 2003;107(1):139-146.

18. Jugdutt BI. Prevention of heart failure in the elderly: when, where and how to begin? Heart Fail Rev. 2012;17(4-5):531-544.

19. Jugdutt BI. Changing demographics of the aging population with heart failure and implications for therapy. In: Jugdutt BI (Ed.), Aging and Heart Failure: Mechanisms and Management, Springer, New York, USA. 2014. p.1-14.

20. Jugdutt BI, Warnica JW. Intravenous nitroglycerin therapy to limit myocardial infarct size, expansion and complications: effect of timing, dosage and infarct location. Circulation. 1988;78(4):906-919.

21. Jugdutt BI, Basualdo CA. Myocardial infarct expansion during indomethacin and ibuprofen therapy for symptomatic post-infarction pericarditis: Effect of other pharmacologic agents during early remodelling. Can J Cardiol. 1989;5(4):211-221.

22. Jugdutt BI. Identification of patients prone to infarct expansion by the degree of regional shape distortion on an early two-dimensional echocardiogram after myocardial infarction. Clin Cardiol. 1990;13(1):28-40.

23. Pfeffer MA, Braunwald E. Ventricular remodelling after myocardial infarction. Circulation. 1990;81(4):1161-1172.
24. Jugdutt BI. Prevention of ventricular remodelling post myocardial infarction: Timing and duration of therapy. Can $J$ Cardiol. 1993;9(1):103-114.

25. Gaudron P, Eilles C, Kugler I, et al. Progressive left ventricular dysfunction and remodeling after myocardial infarction. Potential mechanisms and early predictors. Circulation. 1993; 87(3):755-763.

26. Jugdutt BI. Prevention of ventricular remodeling after myocardial infarction and in congestive heart failure. Heart Failure Reviews. $1996 ; 1: 115-129$

27. Jugdutt BI, Amy RW. Healing after myocardial infarction in the dog: Changes in infarct hydroxyproline and topography. J Am Coll Cardiol. 1986;7(1):91-102.

28. Jugdutt BI, Joljart MJ, Khan MI. Rate of collagen deposition during healing after myocardial infarction in the rat and dog models: mechanistic insights into ventricular remodeling. Circulation. 1996;94:94-101.

29. Jugdutt BI, Khan MI. Impact of increased infarct transmurality on remodeling and function during healing after anterior myocardial infarction in the dog. Can J Physiol Pharmacol. 1992;70(7):949-958.

30. Jugdutt BI, Tang SB, Khan MI, et al. Functional impact on remodeling during healing after non-Q-wave versus Q-wave anterior myocardial infarction in the dog. J Am Coll Cardiol . 1992;20(3):722-731.

31. Jugdutt BI, Jelani A, Palaniyappan A, et al. Aging-related changes in markers of ventricular and matrix remodelling after reperfused STsegment elevation myocardial infarction in the canine model. Effect of early therapy with an angiotensin II type 1 receptor blocker. Circulation. 2010;122(4):341-351.

32. Jelani A, Jugdutt BI. STEMI and heart failure in the elderly: role of adverse remodeling. Heart Fail Rev. 2010;15(5):513-521.

33. Bolognese L, Neskovic AN, Parodi G, et al. Left ventricular remodeling after primary coronary angioplasty: patterns of left ventricular dilation and long-term prognostic implications. Circulation. 2002;106(18):2351-2357.

34. Alexander KP, Newby LK, Armstrong PW, et al. Acute coronary care in the elderly, Part II. ST-segment-elevation myocardial infarction. A scientific statement for healthcare professionals from the American Heart Association Council for Clinical Cardiology. Circulation. 2007;115(19):2570-2589.

35. Man J, Tymchak W, Jugdutt BI. Adjunctive pharmacologic treatment for acute myocardial infarction. In; Brown DL \& Jeremias A (Eds.), Textbook of Cardiac Intensive Care. (2nd edn), Elsevier, Philadelphia, USA. 2010.p. 1-72.

36. Orn S, Manhenke C, Anand IS, et al. Effect of left ventricular scar size, location, and transmurality on left ventricular remodeling with healed myocardial infarction. Am J Cardiol. 2007;99(8):1109-1114.

37. Orn S, Manhenke C, Greve OJ, et al. Microvascular obstruction is a major determinant of infarct healing and subsequent left ventricular remodelling following primary percutaneous coronary intervention. Eur Heart J . 2009;30(16):1978-1985.

38. Ørn S, Manhenke C, Ueland T, et al. C-reactive protein, infarct size, microvascular obstruction, and left-ventricular remodelling following acute myocardial infarction. Eur Heart J . 2009;30(10):1180-1186.

39. Manhenke C, Ueland T, Jugdutt BI, et al. The relationship between markers of extracellular cardiacmatrix turnover. Infarct healing and left ventricular remodelling following primary PCI in patients with firsttime STEMI. Eur Heart J. 2004;35(6):395-402.

40. Bujak M, Kweon HJ, Chatila K, et al. Aging-related defects are associated with adverse cardiac remodeling in a mouse model of reperfused myocardial infarction. J Am Coll Cardiol. 2008;51(14):1384-1392.

41. Nahrendorf M, Pittet MJ, Swirski FK. Monocytes: Protagonists of infarct inflammation and repair after myocardial infarction. Circulation. 2010;121(22):2437-2445. 
42. Palaniyappan A, Uwiera RER, Idikio $\mathrm{H}$, et al. Comparison of vasopeptidase inhibitor omapatrilat and angiotensin II type 1 receptor blocker candesartan on extracellular matrix, myeloperoxidase, cytokines and ventricular remodeling during healing after reperfused myocardial infarction. Mol Cell Biochem. 2009; 321(1-2):9-22.

43. Palaniyappan A, Uweira RRE, Idikio H, et al. Attenuation of increased leucocyte protease inhibitor, matricellular proteins and angiotensin II and left ventricular remodeling by candesartan and omapatrilat during healing after reperfused myocardial infarction. Mol Cell Biochem. 2013;376(1-2):175-188.

44. Jugdutt BI, Palaniyappan A, Uwiera RRE, et al. Role of healing-specificmatricellular proteins and matrix metalloproteinases in age-related enhanced early remodeling after reperfused STEMI in dogs. Mol Cell Biochem. 2009;322(1-2):25-36.

45. Jugdutt BI, Palaniyappan A, Idikio H. Candesartan suppresses increase in secreted frizzled related protein 2 and fibrosis during healing after reperfused myocardial infarction in the rat model. $J$ Am Coll Cardiol. 2010;55(10s 1):A123.

46. Heymes C, Swynghedauw B, Chevalier B. Activation of angiotensinogen and angiotensin-converting enzyme gene expression in the left ventricle of senescent rats. Circulation. 1994;90(3):1328-1333.

47. Heymes C, Silvestre JS, Llorens-Cortes C, et al. Cardiac senescence is associated with enhanced expression of angiotensin II receptor subtypes. Endocrinology. 1998;139(5):2579-2587.

48. Frangogiannis NG, Smith CW, Entman ML. The inflammatory response in myocardial infarction. Cardiovasc Res. 2002;53(1):31-47.

49. Nahrendorf M, Swirski FK, Aikawa E, et al. The healing myocardium sequentially mobilizes two monocyte subsets with divergent and complementary functions. $J$ Exp Med. 2007;204(12):3037-3047.

50. Borregaard N, Cowland JB. Granules of the human neutrophilic polymorphonuclear leukocyte. Blood. 1997;89(10):3503-3521.

51. Mollinedo F, Nakajima M, Llorens A, et al. Major co-localization of the extracellular-matrix degradative enzymes heparanase and gelatinase in tertiary granules of human neutrophils. Biochem $J .1997 ; 327(\mathrm{Pt}$ 3):917-923.

52. Bidouard JP, Duval N, Kapui Z, et al. SSR69071, an elastase inhibitor, reduces myocardial infarct size following ischemia-reperfusion injury. Eur J Pharmacol . 2003;461(1):49-52.

53. YndestadA, Landrø L, Ueland T, et al. Increased systemic and myocardial expression of neutrophil gelatinase-associated lipocalin in clinical and experimental heart failure. Eur Heart J. 2009;30(10):1229-1236.

54. Sahinarslan A, Kocaman SA, Bas D, et al. Plasma neutrophil gelatinaseassociated lipocalin levels in acute myocardial infarction and stable coronary artery disease. Coron Artery Dis. 2011;22(5):333-338.

55. AskariAT, Brennan ML, Zhou X, etal. Myeloperoxidase and plasminogen activator inhibitor 1 play a central role in ventricular remodeling after myocardial infarction. J Exp Med. 2003;197(5):615-624.

56. Brennan ML, Penn MS, Van Lente F, et al. Prognostic value of myeloperoxidase in patients with chest pain. $N$ Engl $\mathrm{J} \mathrm{Med}$. 2003;349(17):1595-1604.

57. Mosser DM, Edwards JP. Exploring the full spectrum of macrophage activation. Nat Rev Immunol. 2008;8(12):958-969.

58. Troidl C, Möllmann $\mathrm{H}$, Nef $\mathrm{H}$, et al. Classically and alternatively activated macrophages contribute to tissue remodelling after myocardial infarction. J Cell Mol Med. 2009;13(9B):3485-3496.

59. Lambert JM, Lopez EF, Lindsey ML. Macrophage roles following myocardial infarction. Int J Cardiol. 2008;130(2);147-158.

60. Hu Y, Zhang H, Lu Y, et al. Class A scavenger receptor attenuates myocardial infarction-induced cardiomyocyte necrosis through suppressing M1 macrophage subset polarization. Basic Res Cardiol. 2011;106(6):1311-1328.
61. Gordon S, Martinez FO. Alternative activation of macrophages: mechanism and functions. Immunity. 2010;32(5):593-604.

62. Weber KT. Cardiac interstitium in health and disease: the fibrillar collagen network. J Am Coll Cardiol. 1989;13(7):1637-1652.

63. Spinale FG. Matrix metalloproteinases: regulation and dysregulation in the failing heart. Circ Res. 2002;90(5):520-530.

64. Spinale FG. Myocardial matrix remodeling and the matrix metalloproteinases: influence on cardiac form and function. Physiol Rev. 2007;87(4):1285-1342.

65. Nagase H, Visse R, Murphy G. Structure and function of Matrix metalloproteinases and TIMPs. Cardiovasc Research 2006;69(3):562-573.

66. Cleutjens JP, Kandala JC, Guarda E, et al. Regulation of collagen degradation in the rat myocardium after infarction. $J$ Mol Cell Cardiol. 1995;27(6):1281-1292.

67. Kim HE, Dalal SS, Young E, et al. Disruption of the myocardial extracellular matrix leads to cardiac dysfunction. J Clin Invest. 2000;106(7):857-866.

68. Foronjy RF, Sun J, Lemaitre V, et al. Transgenic expression of matrix metalloproteinase-1 inhibits myocardial fibrosis and prevents the transition to heart failure in a pressure overload mouse model. Hypertens Res. 2008;31(4):725-735.

69. Creemers EE, Davis JN, Parkhurst AM, et al. Deficiency of TIMP-1 exacerbates $\mathrm{LV}$ remodeling after myocardial infarction in mice. Am J Physiol Heart Circ Physiol. 2003;284(1):H364-H371.

70. Cavusoglu E, Ruwende C, Chopra V, et al. Tissue inhibitor of metalloproteinase-1 (TIMP-1) is an independent predictor of all-cause mortality, cardiac mortality, and myocardial infarction. Am Heart $J$. 2006;151(5):e1101-e1108.

71. López B, González A, Querejeta R, et al. Alterations in the pattern of collagen deposition may contribute to the deterioration of systolic function in hypertensive patients with heart failure. $\mathrm{J} \mathrm{Am}$ Coll Cardiol. 2006;48(1):89-96.

72. Matsumura S, Iwanaga S, Mochizuki S, et al. Targeted deletion or pharmacological inhibition of MMP-2 prevents cardiac rupture after myocardial infarction in mice. J Clin Invest. 2005;115(3):599-609.

73. Lindsey M, Wedin K, Brown MD, et al. Matrix-dependent mechanism of neutrophil-mediated release and activation of matrix metalloproteinase 9 in myocardial ischemia/reperfusion. Circulation. 2001;103(17):2181-2187.

74. Itoh Y, Nagase H. Preferential inactivation of tissue inhibitor of metalloproteinases- 1 that is bound to the precursor of matrix metalloproteinase 9 (progelatinase B) by human neutrophil elastase. $J$ Biol Chem. 1995;270(28):16518-16521.

75. Bidouard JP, Duval N, Kapui Z, et al. SSR69071, an elastase inhibitor, reduces myocardial infarct size following ischemia-reperfusion injury. Eur J Pharmacol . 2003;461(1):49-52.

76. Lindsey ML, Escobar GP, Dobrucki LW, et al. Matrix metalloproteinase-9 gene deletion facilitates angiogenesis after myocardial infarction. Am J Physiol Heart Circ Physiol. 2006;290(1):H232-H239.

77. Blankenberg S, Rupprecht HJ, Poirier O, et al. Plasma concentrations and genetic variation of matrix metalloproteinase 9 and prognosis of patients with cardiovascular disease. Circulation. 2003;107(12):1579-1585.

78. Squire IB, Evans J, Ng LL, et al. Plasma MMP-9 and MMP-2 following acute myocardial infarction in man: correlation with echocardiographic and neurohumoral parameters of left ventricular dysfunction. Journal of cardiac failure. 2004;10(4):328-333.

79. Yan AT, Yan RT, Spinale FG, et al. Plasma matrix metalloproteinase-9 level is correlated with left ventricular volumes and ejection fraction in patients with heart failure. J Card Fail. 2006;12(7):514-519. 
80. Jugdutt BI. Matrix metalloproteinases as markers of adverse remodeling after myocardial infarction. J Card Fail . 2006;12(1):73-76.

81. Martos R, Baugh J, Ledwidge M, et al. Diastolic heart failure: evidence of increased myocardial collagen turnover linked to diastolic dysfunction. Circulation . 2007;115(7):888-895.

82. Fedak PW, Smookler DS, Kassiri Z, et al. TIMP-3 deficiency leads to dilated cardiomyopathy. Circulation. 2004;110(16):2401-2409.

83. Fedak PW, Moravec CS, McCarthy PM, et al. Altered expression of disintegrin metalloproteinases and their inhibitor in human dilated cardiomyopathy. Circulation. 2006;113(2):238-245.

84. Jugdutt B I . Cardiac regeneration and repair. In: Li R \& Weisel RD (Eds.), Pathology and therapies. Wood head publishing, London. 2014; 2(1): 3-26.

85. Diez J. Mechanisms of cardiac fibrosis in hypertension. J Clin Hypertens (Greenwich). 2007;9(7):546-550.

86. Sugihara N, Genda A, Shimizu M, et al. Diastolic dysfunction and its relation to myocardial fibrosis in essential hypertension. J Cardiol 1988;18(2):353-361.

87. Mclenachan JM, Dargie HJ. Ventricular arrhythmias in hypertensive left ventricular hypertrophy. Relationship to coronary artery disease left ventricular dysfunction, and myocardial fibrosis. Am J Hypertens. 1990;3(10):735-740.

88. Wynn TA. Cellular and molecular mechanisms of fibrosis. $J$ Pathol. 2008;214(2):199-221

89. López B, González A, Varo N, et al. Biochemical assessment of myocardial fibrosis in hypertensive heart disease. Hypertension. 2001;38(5):1222-1226.

90. Takino T, Nakamura M, Hiramori K. Circulating levels of carboxyterminal propeptide of type I procollagen and left ventricular remodeling after myocardial infarction. Cardiology. 1999;91(2):81-86.

91. Díez J, Panizo A, Gil MJ, et al. Serum markers of collagen type I metabolism in spontaneously hypertensive rats. Circulation. 1996;93(5):1026-1032.

92. Risteli J, Risteli L. Analysing connective tissue metabolites in human serum. Biochemical, physiological and methodological aspects. $J$ Hepatol. 1995; 22(2 Suppl):77-81.

93. Sharma UC, Pokharel S, van Brakel TJ, et al. Galectin-3 marks activated macrophages in failure-prone hypertrophied hearts and contributes to cardiac dysfunction. Circulation. 2004;110(19):3121-3128.

94. Liu YH, D’Ambrosio M, Liao TD, et al. N-acetyl-seryl-aspartyllysyl-proline prevents cardiac remodeling and dysfunction induced by galectin-3, a mammalian adhesion/growth-regulatory lectin. Am J Physiol Heart Circ Physiol. 2009;296(2):H404-H412.

95. Jugdutt BI. Regulation of fibrosis after myocardial infarction: Implications for ventricular remodeling. In: Jugdutt BI \& Dhalla NS (Eds.), Cardiac Remodeling. Springer media, Inc. New York, USA. 2013. p.525-545.

96. Camelliti P, Borg TK, Kohl P. Structural and functional characterisation of cardiac fibroblasts. Cardiovasc Res. 2005;65(1):40-51.

97. Porter KE, Turner NA. Cardiac fibroblasts: at the heart of myocardial remodeling. Pharmacol Ther. 2009;123(2):255-278.

98. Smith RS, Smith TJ, Blieden TM, et al. Fibroblasts as sentinel cells. Synthesis of chemokines and regulation of inflammation. Am J Pathol . 1997;151(12):317-322.

99. Jugdutt BI. Modulators of remodeling after myocardial infarction. In: Dhalla NS, Nagano M, Ostadal B (Eds.), Molecular Defects in Cardiovascular Disease. Springer media, Inc. New York, USA. 2011. p.231-242.
100. Jugdutt BI, Jelani A. Aging and markers of adverse remodeling after myocardial infarction. In: Jugdutt BI \& Dhalla NS (Eds.), Molecular mechanisms. Springer, New York, USA. 2013. p.487-512.

101. King MK, Coker ML, Goldberg A, et al. Selective matrix metalloproteinase inhibition with developing heart failure: effects on left ventricular function and structure. Circ Res . 2003;92(2):177-185.

102. Hudson MP, Armstrong PW, Ruzyllo W, et al. Effects of selective matrix metalloproteinase inhibitor (PG-116800) to prevent ventricular remodeling after myocardial infarction: results of the PREMIER (Prevention of Myocardial Infarction Early Remodeling) trial. J Am Coll Cardiol. 2006;48(1):15-20.

103. Solomon SD, Zile M, Pieske B, et al. The angiotensin receptor neprilysin inhibitor LCZ696 in heart failure with preserved ejection fraction: a phase 2 double-blind randomized clinical trial. Lancet. 2012;380(9851):1387-1395.

104. McMurray JJ, Packer M, Desai AS, et al. Dual angiotensin receptor and neprilysin inhibition as an alternative to angiotensin-converting enzyme inhibition in patients with chronic systolic heart failure: rationale for and design of the Prospective comparison of ARNI with ACEI to determine impact on global mortality and morbidity in patients with heart failure trial (PARADIGM-HF). Eur J Heart Fail . 2013;15(9):1062-1073.

105. Jugdutt BI. Aging and remodeling of the RAS and RAAS and related pathways: Implications for heart failure therapy. Aging and Heart Failure, Springer, New York, USA. 2014. p.259-289.

106. Anversa P, Palackal T, Sonnenblick EH, et al. Myocyte cell loss and myocyte hypertrophy in the aging rat heart. Circ Res. 1990;67(4):871-885.

107. Olivetti G, Melissari M, Capasso JM, et al. Cardiomyopathy of the aging human heart. Myocyte loss and reactive cellular hypertrophy. Circ Res. 1991;68(6):1560-1568.

108. Vaziri SM, Larson MG, Benjamin EJ, et al. Echocardiographic predictors of nonrheumatic atrial fibrillation. The Framingham Heart Study. Circulation. 1994; 89(2):724-730.

109. Lam CS, Roger VL, Rodeheffer RJ, et al. Cardiac structure and ventricular-vascular function in persons with heart failure and preserved ejection fraction from Olmsted County, Minnesota. Circulation. 2007;115(15):1982-1990.

110. Reed AL, Tanaka A, Sorescu D, et al. Diastolic dysfunction is associated with cardiac fibrosis in the senescence-accelerated mouse. Am J Physiol Heart Circ Physiol. 2011;301(3):H824-H831.

111. Hulbert AJ, Pamplona R, Buffenstein R, et al. Life and death: metabolic rate, membrane composition, and life span of animals. Physiol Rev. 2007;87(4):1175-1213.

112. Grimes KM, Lindsey ML, Gelfond JA, et al. Getting to the heart of the matter: age-related changes in diastolic heart function in the longestlived rodent, the naked mole rat. J Gerontol A Biol Sci Med Sci. 2012;67(4):384-394.

113. Candido R, Forbes JM, Thomas MC, et al. A breaker of advanced glycation end products attenuates diabetes-induced myocardial structural changes. Circ Res. 2003;92(7):785-792.

114. Hartog JW, Voors AA, Bakker SJ, et al. Advanced glycation end-products (AGEs) and heart failure: Pathophysiology and clinical implications. Eur J Heart Fail. 2007;9(12):1146-1155.

115. McCurdy S, Baicu CF, Heymans S, et al. Cardiac extracellular matrix remodeling: fibrillar collagens and Secreted Protein Acidic and Rich in Cysteine (SPARC). J Mol Cell Cardiol. 2010;48(3):544-549.

116. Bradshaw AD, Baicu CF, Rentz TJ, et al. Pressure overload-Induced alterations in fibrillar collagen content and myocardial diastolic function. Circulation. 2009;119(2):269-280. 
117. Bradshaw AD, Baicu CF, Rentz TJ, et al. Age-dependent alterations in fibrillar collagen content and myocardial diastolic function: role of SPARC in post-synthetic procollagen processing. Am J Physiol Heart Circ Physiol. 2010;298(2):H614-H622.

118. Schellings MW, Vanhoutte D, Swinnen M, et al. Absence of SPARC results in increased cardiac rupture and dysfunction after acute myocardial infarction. J Exp Med. 2009;206(1):113-123.

119. Mohan S, Radha E. Age related changes in muscle connective tissue: acid mucopolysaccharides and structural glycoprotein. Exp Gerontol. 1981;16(5):385-392.

120. von Knorring J. The mucopolysaccharides in the myocardium of growing rats. Acta Physiol Scand. 1970;79(2):226-237.

121. Huynh MB, Morin C, Carpentier G, et al. Age-related changes in rat myocardium involve altered capacities of glycosaminoglycans to potentiate growth factor functions and heparan sulfate-altered sulfation. J Biol Chem. 2012;287(14):11363-11373.

122. Ahumada GG, Saffitz JE. Fibronectin in rat heart: a link between cardiac myocytes and collagen. J Histochem Cytochem. 1984;32(4):383-388.

123. Samuel JL, Barrieux A, Dufour S, et al. Accumulation of fetal fibronectin mRNAs during the development of rat cardiac hypertrophy induced by pressure overload. J Clin Invest. 1991;88(5):1737-1746.

124. Philips N, Bashey RI, Jimenez SA. Collagen and fibronectin expression in cardiac fibroblasts from hypertensive rats. Cardiovasc Res. 1994;28(9):1342-1347.

125. Dobaczewski M, Gonzalez-Quesada C, Frangogiannis NG. The extracellular matrix as a modulator of the inflammatory and reparative response following myocardial infarction. $J \mathrm{Mol}$ Cell Cardiol. 2010;48(3):504-511.

126. Thomas DP, McCormick RJ, Zimmerman SD, et al. Aging-and traininginduced alterations in collagen characteristics of rat left ventricle and papillary muscle. Am J Physiol Heart Circ Physiol. 1992;263(3 Pt 2):H778-H783.

127. Thomas DP, Zimmerman SD, Hansen TR, et al. Collagen gene expression in rat left ventricle: interactive effect of age and exercise training. J Appl Physiol. 2000; 89(4):1462-1468.

128. Capasso JM, Palackal T, Olivetti G, et al. Severe myocardial dysfunction induced by ventricular remodeling in aging rat hearts. Am J Physiol Heart Circ Physiol. 1990;259(4 Pt 2):H1086-H1096.

129. Lin J, Lopez EF, Jin Y, et al. Age-related cardiac muscle sarcopenia: Combining experimental and mathematical modeling to identify mechanisms. Exp Gerontol. 2008;43(4):296-306.

130. Bonnema DD, Webb CS, Pennington WR, et al. Effects of age on plasma matrix metalloproteinases (MMPs) and tissue inhibitor of metalloproteinases (TIMPs). J Card Fail. 2007;13(7):530-540.

131. Boon RA, Iekushi K, Lechner S, et al. MicroRNA-34a regulates cardiac ageing and function. Nature . 2013;495(7439):107-110.
132. Pluim BM, Lamb HJ, Kayser HW, et al. Functional and metabolic evaluation of the athlete's heart by magnetic resonance imaging and dobutamine stress magnetic resonance spectroscopy. Circulation. 1998;97(7):666-672.

133. Ma Y, Chiao YA, Zhang J, et al. Matrix metalloproteinase-28 deletion amplifies inflammatory and extracellular matrix responses to cardiac aging. Microsc Microanal. 2012;18(1):81-90.

134. Ma Y, Halade GV, Zhang J, et al. Matrix metalloproteinase-28 deletion exacerbates cardiac dysfunction and rupture after myocardial infarction in mice by inhibiting M2 macrophage activation. Circ Res. 2013;112(4):675-688

135. Horn MA, Graham HK, Richards MA, et al. Age-related divergent remodeling of the cardiac extracellular matrix in heart failure: Collagen accumulation in the young and loss in the aged. $J$ Mol Cell Cardiol. 2012;53(1):82-90.

136. Butler J, Fonarow GC, Zile MR, et al. Developing therapies for heart failure with preserved ejection fraction: Current state and future directions. JACC Heart Fail. 2014;2(2):97-112.

137. Campbell RT, Jhund PS, Castagno D, et al. What have we learned about patients with heart failure and preserved ejection fraction from DIG-PEF, CHARM preserved, and I-PRESERVE? J Am Coll Cardiol. 2012;60(23):2349-2356.

138. Zile MR, Gaasch WH, Anand IS, et al. Mode of death in patients with heart failure and a preserved ejection fraction: results from the Irbesartan in Heart Failure With Preserved Ejection Fraction Study (I-Preserve) trial. Circulation. 2010;121(12):1393-1405.

139. Solomon SD, Anavekar N, Skali H, et al. Influence of ejection fraction on cardiovascular outcomes in a broad spectrum of heart failure patients. Circulation . 2005;112(24):3738-3744.

140. Paulus WJ, Tschope C. A novel paradigm for heart failure with preserved ejection fraction: comorbidities drive myocardial dysfunction and remodeling through coronary microvascular endothelial inflammation. J Am Coll Cardiol. 2013;62(4):263-271.

141. Zile MR, Gaasch WH, Patel K, et al. Adverse left ventricular remodeling in community-dwelling older adults predicts incident heart failure. JACC Heart Fail. 2014;2(5):512-522.

142. Zile MR, Gottdiener JS, Hetzel SJ, et al. Prevalence and significance of alterations in cardiac structure and function in patients with heart failure and a preserved ejection fraction. Circulation. 2011;124(23):2491-2501.

143. Cheng JM, Akkerhuis KM, Battes LC, et al. Biomarkers of heart failure with normal ejection fraction: a systematic review. Eur J Heart Fail. 2013;15(12):1350-1362.

144. Bayes-Genis A, Januzzi JL, Gaggin HK, et al. ST2 pathogenetic profile in ambulatory heart failure patients. $J$ Card Fail. 2015;21(4):355-361. 